\title{
Interface for modeling the power output of a small wind turbine
}

K. R. Ajao, M. R. Mahamood and M.O. Iyanda ${ }^{1}$

\author{
Dept. of Mech. Engineering, ${ }^{1}$ Dept. of Agric. \& Biosystem Engineering, University of Ilorin, Ilorin, Nigeria \\ ajaomech@unilorin.edu.ng, mahamoodmr@unilorin.edu.ng, iyandamo@yahoo.com
}

\begin{abstract}
Wind power is one of the world's fastest growing energy sources. A program was developed using Visual Basic 6.0 to model a small wind turbine drive train and power output before it is being fabricated, deployed and tested.
\end{abstract}

Keywords: Wind power, program, model wind turbine

\section{Introduction}

All forms of wind turbine are designed to extract power from a moving air stream. The dynamic loads on wind turbines can result in significant mechanical problems such as the failure of gears, pinions, bearings and other components due to fatigue. There is clearly a need for modeling and simulation tools that can model wind turbine behavior and power output before a wind turbine is being fabricated, deployed and tested.

The blades have an airfoil cross-section and extract wind by a lift force caused by a pressure difference between blade sides. When air passes over an airfoil section; it travels faster over the top of the blade than it does below it. This makes the air pressure above the blade lower than it is below and due to the unequal pressures the blade experiences a lifting force.

Almost all wind turbine that produce electricity consists of rotor blades that rotate around a horizontal hub. The hub is connected to a gearbox and a generator (direct-drive generators are without gearbox) which are located inside a nacelle. The nacelle houses some of the electrical components and it is mounted on top of the tower. Many different design concepts are in use. The most common ones are two-bladed or three-bladed, stall or pitch regulated, horizontal-axis machines working at variable or near fixed rotation speed.

\section{Wind turbine characteristics}

Wind is merely air in motion. It is produced by the uneven heating of the Earth's surface by energy from the Sun. Since the Earth's surface is made of different types of land and water, it absorbs the Sun's radiant energy at different rates. Much of this energy is converted into heat as it is absorbed by land areas, bodies of water and the air over the Earth surface.

The energy available in wind depends on the density and air velocity. The density, as any other gas, changes with the temperature and pressure which varies with the height over the sea level. The energy of a mass of air which is displaced is determined by the cube law (Victor et al., 2004).

$P_{0}=\frac{1}{2} \rho A V^{3}$
The conversion mechanism of energy in wind turbines is achieved by the deceleration of free wind stream.

When the wind move across the wind turbine, the static pressure drops to a lower pressure than the atmospheric pressure. As the air follows its trajectory, it takes its atmospheric value again, inducing an extra wind deceleration. By this way, in a distance between upstream of the turbine and downstream, behind the turbine, there is no change in static pressure, but there is a reduction in kinetic energy. This phenomenon is represented by the Betz law.

$P_{M A X}=\frac{8}{27} \rho A V^{3}$

Wind turbine blades: The mechanical power produced by a rotor is purely a function of the blade geometry and the incident velocity. The design parameters that affect aerodynamic performance include blade pitch (angle of attack), taper, and twist distribution. For a given blade, its geometric shape is usually fixed, i.e. the aerodynamic shape, taper and twist distribution do not change. The $C_{p}$ for any fixed rotor geometry is a well-prescribed function of the blade tip speed ratio with a single maximum value.

The gearbox: The gearbox is required to speed up the slow rotational speed of the low speed shaft before connection to the generator. The speed of the blade is limited by efficiency and also by limitations in the mechanical properties of the turbine and supporting structure. The gearbox ratio depends on the number of poles and the type of generator. A direct driven generator (without gearbox) would require a generator with 600 poles to generate electricity at $50 \mathrm{~Hz}$.

Historically, gearboxes have been problematic for wind turbines. The fluctuating aerodynamic loads are difficult to accurately predict. Thus, designers compensate for unknown loads with large safety factor (Cotrell, 2002).

The recent trend toward large turbines has led to very expensive gearboxes. The gearboxes for these wind turbines are more expensive per kilowatt than for smaller wind turbines because the torque, which is the primary cost driver, increase more quickly than the power for a given increases in rotor diameter. The rotor torque tends to increase as a cube of the rotor diameter while the power only increases with the square of the diameter. This is because large wind turbine rotors operate at slower rotational speeds (to limit aero-acoustic noise) but produce more power. Gearboxes also require significant maintenance. Most of the larger machines are intended 
for offshore use where the trend has been toward very low maintenance designs.

Generators: The generator used in geared wind turbines are more or less standard off-the-shelf electrical machines, so that major development steps were not necessary. There are different types of generators depending on their configuration and areas of application.

The wind turbine generator converts mechanical energy to electrical energy. The efficiency of an electrical generator usually falls off rapidly below its rated output. Since the power in the wind fluctuates widely, it is important to consider the relation between rated wind speed and rated power.

With the important exception of electrostatic generators such as the Van de Graf machine, all important schemes for converting mechanical motion into electrical energy depends on Faraday's Law of electromagnetic induction (Carlin et al., 2001). The phenomenon of inducing a current by changing the magnetic field in a coil of wire is known as electromagnetic induction which underpins the design of most electric generators (Cotrell, 2002).

The tower. The most common types of tower are the lattice and tubular types constructed from steel or concrete. For small wind turbine the tower may be supported by guy wires. The tower can be designed in two ways, soft or stiff. A stiff tower has a natural frequency which lies above the blade passing frequency. Soft towers are lighter and cheaper but have to withstand more movement and will suffer higher stress levels.

Most modern wind turbines have conical towers made of steel. The tubular shape allows access from inside the tower to the nacelle, which is preferred in bad weather conditions. Lattice towers are assembled by welded steel profiles; they are cheap but the main disadvantages are the poor appeal and that the access to nacelle is exposed.

Output power control. Wind turbines are expected to produce electricity as cheaply as possible. They are designed to yield maximum output (rated power) at a speed around $10 \mathrm{~m} / \mathrm{s}$ to $15 \mathrm{~m} / \mathrm{s}$ (rated wind speed). As the wind speed increases above the rated speed of the turbine, the control mechanism of the rotor limits the power drawn from the wind, mostly in large turbines in order to keep the drive train torque constant.

To avoid damage to the generator and excessive mechanical stresses, the wind turbine is shut off when reaching a predetermined speed normally about $25 \mathrm{~m} / \mathrm{s}$ known as the cut-out speed.

The wind resource: Wind is simply air in motion. It is produced by the uneven heating of the earth's surface by energy from the sun. Since the earth's surface is made of very different types of land and water, it absorbs the sun's radiant energy at different rates. Much of this energy is converted into heat as it is absorbed by land areas, bodies of water, and the air over these formations (NPSEI, 2007). On the coast, for example, the land heats

up more quickly than the water. The warm air over the

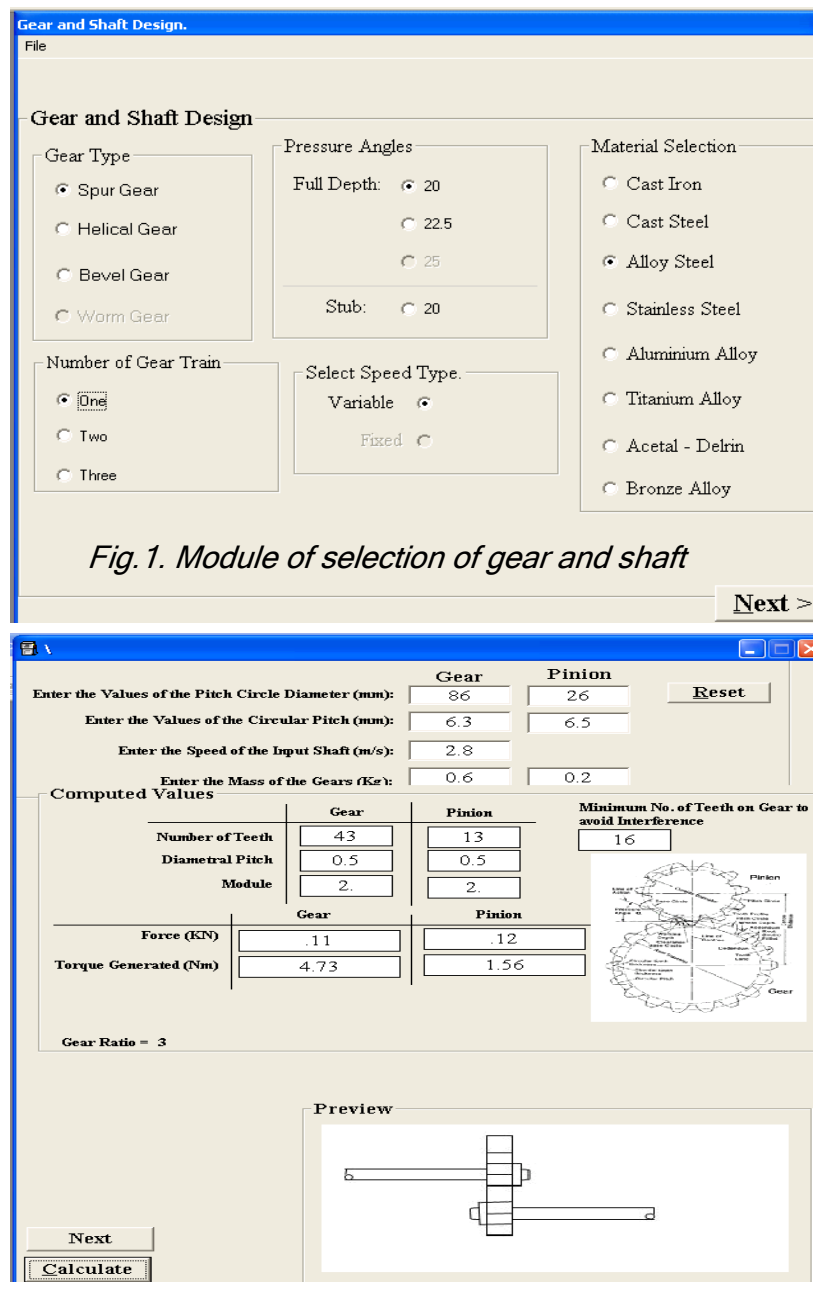

Fig. 2. Module of design parameter for gear and pinion

\begin{tabular}{|c|c|}
\hline Enter Rotor Diameter in $\mathrm{mm}$ & 2154 \\
\hline Enter Hub Diameter in $\mathrm{mm}$ & 154 \\
\hline Enter Height of Tower in $\mathrm{mm}$ & 14900 \\
\hline Enter Blade Thickness in $\mathrm{mm}$ & 24 \\
\hline Enter Tower Diameter in $\mathrm{mm}$ & 150 \\
\hline Enter Rotor Swept Area & 3.65 \\
\hline Enter Wind Speed in in $\mathrm{m} / \mathrm{s}$ & 10 \\
\hline \multicolumn{2}{|l|}{ View Density of Air } \\
\hline Enter Total Time of Operation in hrs & 6 \\
\hline 0.59 Betzlimit & \\
\hline 0.5 (Car Alternator) & \\
\hline 0.9 & Calculate Power \\
\hline \multicolumn{2}{|l|}{$\begin{array}{l}\text { Power }=593.56 \text { watts } \\
\text { Energy }=3.56 \mathrm{Kw} / \mathrm{hr}\end{array}$} \\
\hline \begin{tabular}{l|l} 
Menu & Reset
\end{tabular} & Next $>$ \\
\hline
\end{tabular}

Fig.3. Module of model turbine power output 
land expands and rises, and the heavier, cooler air over the water rushes in to take its place, creating wind. In the same way, the large atmospheric winds that circle the earth are produced because the earth's surface near the

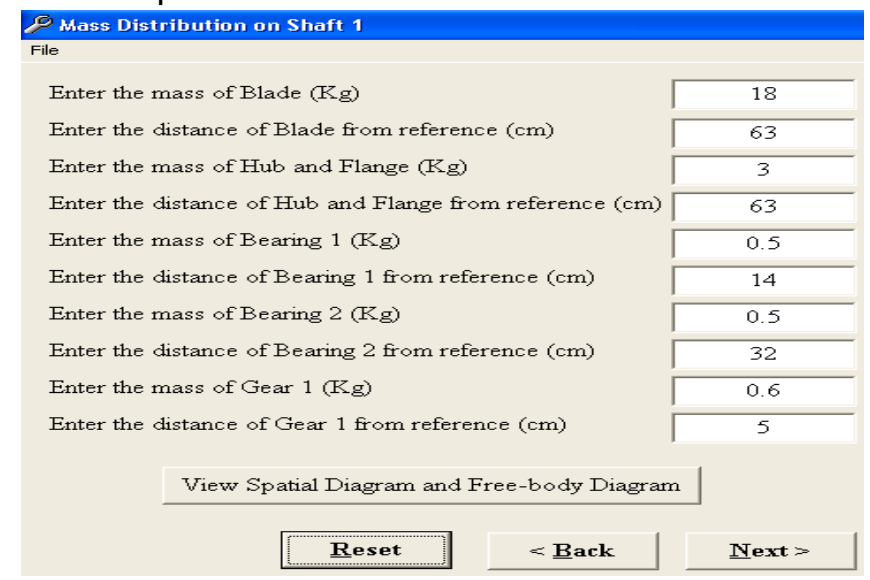

Fig.4. Module showing mass distribution on low speed shaft

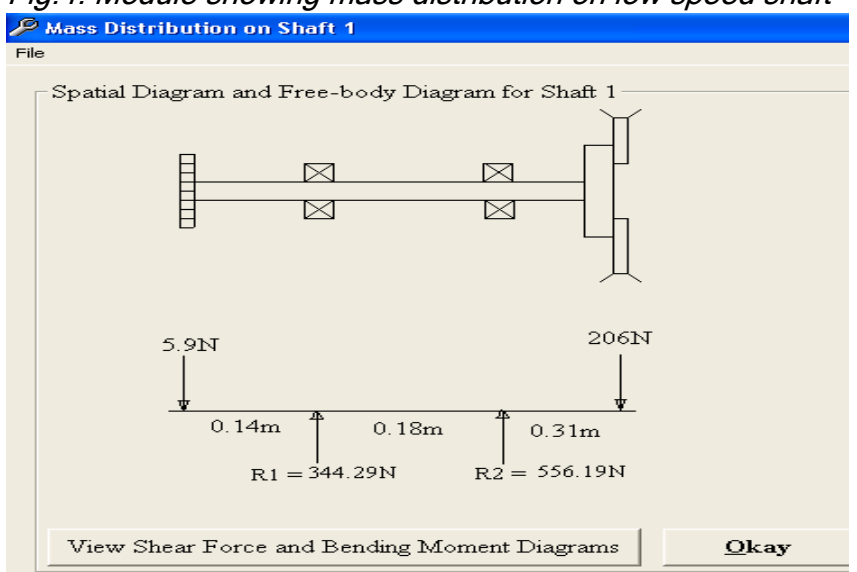

Fiq. 5. Module of free body diagram for low speed shaft

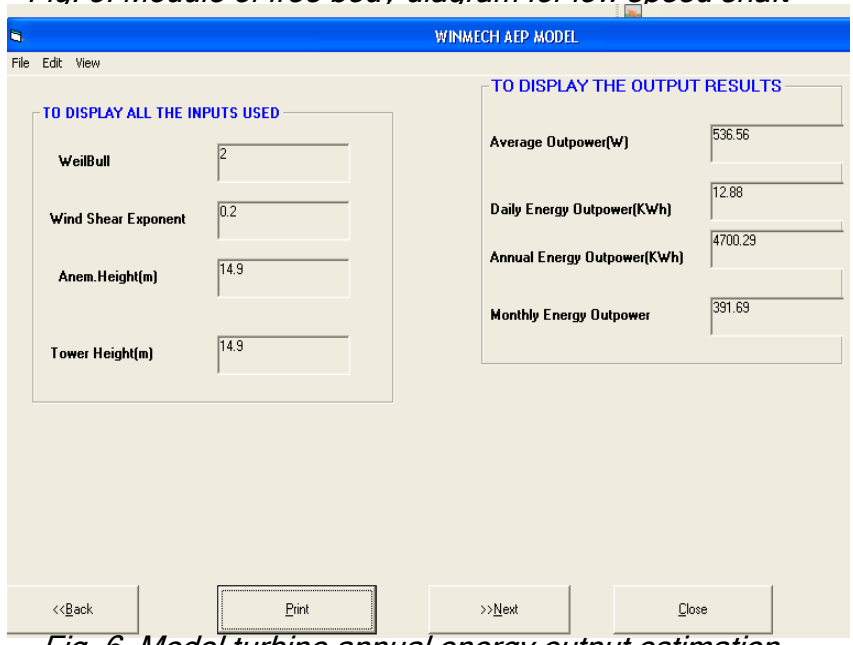

Fig. 6. Model turbine annual energy output estimation

equator receives more of the sun's energy than the surface near the North and South poles. Wind characteristics depend upon numerous factors such as topography, site elevation above sea level, surface
Vol.2 No 5 (May 2009)

ISSN: 0974- 6846

roughness and location exposure to any prevailing winds (Farruiga et al., 2005). Wind speed increases with height above ground level at the specific site itself, calling for wind speed measurements at a height representative of a wind turbine hub height. Based upon current wind turbine technology, the first one hundred metres $(100 \mathrm{~m})$ of the lower atmospheric boundary layer is the prime area of interest.

\section{Modeling the wind turbine}

Wind turbine aerodynamic loads routinely exhibit startling spatial and temporal complexities, driven by the combined influence, of three-dimensionality, unsteadiness, and dynamic separation. Threedimensional cross flows as well as quasi-steady and unsteady separation event arise from both the stochastic nature of the inflow and the components of the turbine architecture.

Most wind turbine structural design codes rely on Blade Element Momentum theory to simulate turbine aerodynamic performance. These algorithms allow the aerodynamics model to run quickly, enabling practical design trade-off analyses. The use of empirical twodimensional wind tunnel test data to obtain quasi-static aerodynamic loads and necessary assumptions associated with Blade Element Momentum theory prevent these models from capturing full three-dimensional effects.

These aerodynamics models include dynamic stall models also empirically derived using two-dimensional wind tunnel test data collected from pitching and plunging type motion. It is not clear, however, if the resulting integrated aerodynamics models sufficiently capture the actual fluid dynamics of highly three-dimensional, dynamically separated flows. Nor is it clear to what degree these models are able to produce adequate predictions experienced in the full operating envelope of a field environment.

Most analysts and designers agree that aerodynamic model predictions in such flow regimes are suspect, and should be used only with appropriate safety factors on design and field experiment. It is also uncertain that sufficiently detailed field measurements exist for validating aerodynamics model against the actual threedimensional, unsteady fluid dynamics.

On the other hand, full-scale experiments (which are mostly field experiments) are put at a disadvantage by wind shear, turbulence, changing oncoming wind in both strength and direction on the exposure of physical phenomena.

Capturing the characteristics and nuances of threedimensional flow separation in a stochastic inflow environment on a large piece of rotating machinery poses as significant a challenge as understanding the underlying fluid mechanics. 
A number of design codes have been used over the last decade to model the wind turbine's dynamic behaviour. They carry out design calculations or develop dynamic and steady state models for all components within a wind turbine. In a longer term, they can be used in a complete optimization of a wind turbine system including models for mechanical part (wind, drive train,

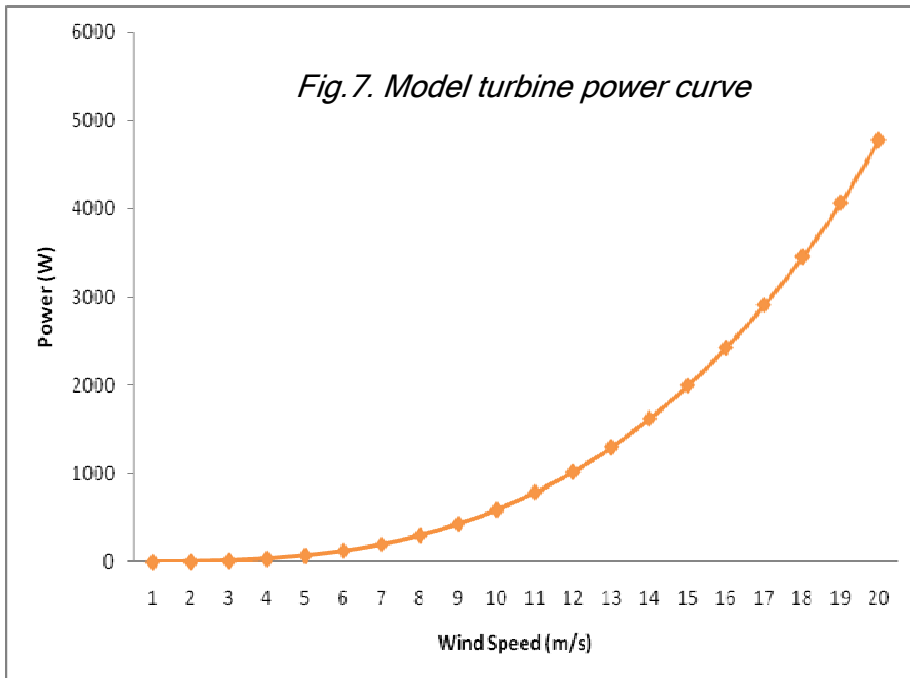

stall and variable pitch control),model for generators (induction generator, synchronous generator, permanent magnet generator), and models for power converters, transformers, and the grid (Florin et al., 2004).

The Visual Basic program was written because of its flexibility and ease of its accessibility in formulating the design to suit the desired objective. The package made it possible to break the program into modules and the results of each of these modules can either be printed or saved.

Some of the guiding equations used in writing the program include equations 1 and 2 and other equations for gear and shaft designs as stated below:

Gear design: Gear is a mechanism which by means of meshing teeth transmit and converts motion, changing the angular velocity and torque between two moving system. It can be used to transmit motion between shafts with parallel, intersecting, non-parallel or crossed axes depending on the types of gear (Abioye, 2001).

The AGMA/Buckingham equation for gear spur design (Abioye, 2001) is given as:

$\left[\frac{F_{t} k_{0} k_{v} k_{m}}{b d_{1} I}\right]^{\frac{1}{2}} \leq \frac{S_{H} C_{F} C_{H} C_{T} C_{R}}{C_{M}}$

The centre distance is given as:

$d=\frac{d_{1}+d_{2}}{2}$

The moment of tangential force or torque supplied by the gear is given as:

The minimum number of teeth on gear to avoid interference is given as:

$n_{0}=\frac{2 k}{(1+2 n) \sin ^{2} \phi}\left(n+\sqrt{n^{2}}+(1+2 n) \sin ^{2} 2 \phi\right)$

Shaft design: A shaft is a mechanical device for transferring power from an engine to a point where useful work is applied. Most engines deliver power as torque through rotary motion. Shafts are carriers of torque; they are subjected to torsion and shear stresses which represent the difference between the input force and the load. They thus need to be strong to bear stress, without imposing too great an additional inertia by virtue of the weight of the shaft (Driveshaft and torque transmission: accessed at http: //en.wikipedia.org/. on $18^{\text {th }}$ July, 2007).

Shafts are usually circular in cross-section and may be either hollow or solid. Since the polar and bending moment of inertia are proportional to the fourth power of the diameter of a circular shaft and the cross sectional area is proportional to the second power of the diameter, a hollow shaft can carry ninety percent of the torque capability of a solid shaft with much less weight.

The maximum shear equation for a hollow shaft (Abioye, 2001) is given as:

$d_{\text {out }}^{3}=\frac{16}{\pi S_{s}\left(1-k^{4}\right)} \sqrt{\left(k_{b} M_{b}+\frac{\alpha_{0} F_{a} d_{0}\left(1+k_{0}^{2}\right)}{8}\right)^{2}+\left(k_{t} M_{t}\right)^{2}}$

For a solid shaft:

$d^{3}=\frac{16}{\pi S_{s}} \sqrt{\left(k_{b} M_{b}\right)^{2}+\left(k_{t} M_{t}\right)^{2}}$

$k_{0}=\frac{d_{\text {in }}}{d_{\text {out }}}$

From the ASME code for commercial steel shafting,

$S_{\text {s(allowable })}=55 \times 10^{6}\left(\mathrm{~N} / \mathrm{m}^{2}\right)$ for shaft without keyway

$S_{\text {s(allowable })}=40 \times 10^{6}\left(\mathrm{~N} / \mathrm{m}^{2}\right)$ for shaft with keyway

$\alpha_{o}=$ column action factor $=1$ for tensile load

Some of the modules generated using the equations above are depicted in the Fig. 1 to 5 .

\section{Results and discussions}

The input parameters to the Visual Basic program (WINMECH) and the output results at the rated wind speed of $10 \mathrm{~m} / \mathrm{s}$ and operating time of six (6) hours per 
day is depicted in Table 1. The expected annual energy production (AEP) for the model turbine can be estimated at rated wind speed (Fig.6). IEC 61400-1 recommend a shape factor $k=2$ which is close to the value found at most of land sites. However a good approximation of the future wind speeds can be made based on historical wind data, which can be directly applied if the historical data is available for that particular site.

The wind speed probability is calculated as a Weibull curve defined by the average wind speed and a shape factork. For each wind speed, instantaneous wind turbine power $(\mathrm{W})$ is multiplied by the Weibull wind speed probability (f). This cross product (net $W$ ) is the contribution of wind speeds to average turbine power output. The sum of these contributions is the average power output of the turbine on a continuous 24 hours basis. Air density factor is the reduction from sea level performance.

The amount of power that a wind turbine produces depends on the wind speed at the time. The power curve describes (Fig.7) the relationship between the wind speed and the power that the turbine generates.

\section{Conclusion}

A small horizontal-axis wind turbine is analyzed by a program developed using Visual Basic 6.0 and referred to as WINMECH. The simulation results are being used in the fabrication of the wind turbine. The fabricated machine will be tested and the experimental results will be reported soon.

\section{References}

1. Abioye AM (May, 2001). Design of engineering power transmission elements using Visual Basic. Unpublished M.Eng. Thesis, Department of Mechanical Engineering, University of llorin.

2. Carlin PW, Laxson AS and Muljadi EB (February, 2001).The history and state of art of variable-speed wind turbine technology. NREL/TP-500-28607, Technical Report.

3. Cotrell J, (January, 2002). A preliminary evaluation of a multiple-generator drive train configuration for wind turbines. NREL/CP-500-31178.

4. Farruiga RN, Fsadni $M$, Yousif $C$ and Mallia EA (2005). The Renewable Energy Potential of the Maltese Islands. XjenZa.10, 32-42.

5. Florin I, Anca DH, Clemens J, Poul S and Frede B (March, 2004). Advanced tools for modeling, design
Vol.2 No 5 (May 2009)

ISSN: 0974- 6846

and optimization of wind turbine system. Conf. Proc., Nordic Wind Power Conference, Chamlers University of Technology, Finland.

6. The Need Project, Secondary Energy Infobook (NPSEI) (September, 2007), MANASSAS, VA.

7. Victor L, Ricardo A (2004). Interfas TIMEO - ANSYS, for the modeling one and modal analysis of an airfoil of turbine of wind. IV Conferencia de Diseño e Ingeniería por Computadora, San Miguel de Allende.

\section{Nomenclature}

$A=$ Area through which the wind passes normally $\left(\mathrm{m}^{2}\right)$

$b=$ gear width $(\mathrm{m})$

$C_{F}=$ Life factor $=1$ for $\mathrm{n}>10^{7}$ cycle, $C_{H}=$ Hardness factor $=1$ for $\mathrm{N}_{1} / \mathrm{N}_{2}<2, \quad C_{T}=$ Temperature factor $=344 /$ $\left(273+\mathrm{T}^{0} \mathrm{C}\right)$ for high temperature, $C_{R}=$ Reliability factor, $C_{M}=$ Material factor

$d_{1}=$ pitch diameter of the pinion $(\mathrm{m}), d_{2}$ is the pitch diameter of gear $(\mathrm{m}), d_{\text {out }}=$ shaft outside diameter $(\mathrm{m})$,

wind speed

\begin{tabular}{|c|c|c|}
\hline $\begin{array}{c}\text { Wind } \\
\text { Speed } \\
(\mathrm{m} / \mathrm{s})\end{array}$ & $\begin{array}{c}\text { Output } \\
\text { Power } \\
\text { (W) }\end{array}$ & $\begin{array}{l}\text { Expected Energy output } \\
\text { at 6 hours of Operation } \\
\text { (kW/hr) }\end{array}$ \\
\hline 1 & 0.59 & 0.00 \\
2 & 4.75 & 0.03 \\
3 & 16.03 & 0.10 \\
4 & 37.99 & 0.23 \\
5 & 74.19 & 0.45 \\
6 & 128.21 & 0.77 \\
7 & 203.59 & 1.22 \\
8 & 303.90 & 1.82 \\
9 & 432.70 & 2.60 \\
10 & 593.56 & 3.56 \\
11 & 790.03 & 4.74 \\
12 & 1025.67 & 6.15 \\
13 & 1304.05 & 7.82 \\
14 & 1628.72 & 9.77 \\
15 & 2003.26 & 12.02 \\
16 & 2431.22 & 14.59 \\
17 & 2916.15 & 17.50 \\
18 & 3461.63 & 20.43 \\
19 & 4071.22 & 24.43 \\
20 & 4784.47 & 28.49 \\
\hline
\end{tabular}

$d_{\text {in }}=$ shaft internal diameter

$F_{t}=$ Tangential force $(\mathrm{N})$

$k=1$ for full depth teeth, $k_{b}=$ combined shock and fatigue factor applied to bending moment, $\quad k_{0}=$ overloading factor depending on the uniformity of the load, $k_{m}=$ mounting factor, $k_{t}=$ combined shock and fatigue factor applied to torsional moment,

$k_{v}=$ velocity factor $=1$ for high

precision gears

$m$ = gear module $(\mathrm{m})$

$M_{b}=$ Bending moment $(\mathrm{Nm})$

$M_{t}=$ Torsional moment $(\mathrm{Nm})$

$n=$ Pinion to gear ratio

$\mathrm{N}_{1}=$ number of teeth of pinion

$\mathrm{N}_{2}=$ number of teeth of gear

$P_{T}=$ Power transmitted $(\mathrm{W})$

$S_{H}=$ contact fatigue strength

$\rho=$ Air density

$\omega_{1}=$ Speed of driving shaft (rev/min)

$\omega_{R}=$ speed ratio, $\mathrm{N}_{1} / \mathrm{N}_{2}$

$V=$ Velocity of wind $(\mathrm{m} / \mathrm{s})$

$\phi=$ Pressure angle $\left(20^{\circ}\right.$ for spur gear $)$ 